\title{
Ultraestructura de la vascularización placentaria en pacientes eclámpticas
}

\author{
Rodrigo Cifuentes*; Hugo Ramírez**; Alejandro Arroyave***; Giovanni Ruiz****
}

\section{RESUMEN}

OBJETIVO: Investigar las alteraciones vasculares en placentas de pacientes eclámpticas.

DISEÑO: Estudio descriptivo, 10 embarazadas normales y 10 eclámpticas, atendidas en el Servicio de Partos, Hospital Universitario del Valle, Cali, Colombia. Se realizó estudio histológico de la placenta, utilizando microscopía de luz, microscopía electrónica de barrido y microscopía electrónica de transmisión.

RESULTADOS: Hallazgo característico en las pacientes eclámpticas es la presencia de necrosis fibrinoide y el depósito de material amorfo intramural, así como la disminución o estenosis del calibre de los vasos sanguíneos por engrosamiento de la capa media. Con microscopía de transmisión se observó marcado daño en el citoplasma, con presencia de vacuolas lipídicas y alteración en las organelas principalmente en el retículo endoplásmico rugoso.

CONCLUSIONES: Lo anterior podría contribuir a explicar el disbalance en los productos endoteliales vasomotores (aumento de tromboxano, endotelina, angiotensina y disminución de prostaciclina y óxido nítrico) que se manifiesta clínicamente como preeclampsia.

PALABRAS ClAVES: Placenta, eclampsia, necrosis, estenosis, vasomotores.

\section{SUMMARY}

OBJECTIVE: To investigate the vascular alterations in the placenta of eclamptic patients.

DESIGN: Descriptive study, 10 normal pregnants and 10 eclamptic at the Hospital Universitario del Valle, Cali, Colombia. Hystological study of the placenta, to using light microscopy, scanning electron microscopy and transmission electron microscopy.

RESULTS: Characteristic finding in the eclamptic patients is the presence of fibrinoid necrosis and the deposit of amorphous intramural material. Also the stenosis of the blood vessels due to enlargement of the media layer. With transmission electron microscopy there is evident an extensive damage in the cytoplasm, with presence of lipidic vacuoles and altered organels, principally the wrinkled endoplasmic reticulum.

CONCLUSIONS: The last may contribute to explain the alterations in vasomotor endothelial substances (increased thromboxane, endothelin and diminished prostacyclin and nitric oxid) clinically expressed as preeclampsia.

KEY WORDS: Placenta, eclampsia, necrosis, stenosis, vasomotor.

\section{Objetivo}

Investigar las alteraciones vasculares en placentas de pacientes con eclampsia comparadas con placentas de embarazadas normales.

Profesor Titular. Jefe Departamento Ginecología y Obstetricia Escuela de Medicina. Universidad del Valle, Cali.

Profesor Titular. Jefe Departamento de Morfología. Facultad de Medicina. Universidad Libre, Cali.

Profesor Titular de Histología. Facultad de Medicina. Universidad Libre, Cali.

Jefe de Residentes. Departamento de Ginecología y Obstetricia. Escuela de Medicina. Universidad del Valle, Cali.

\section{Diseño}

Estudio histológico en microscopía de luz, microscopía electrónica de barrido y microscopía electrónica de transmisión.

\section{Lugar}

Servicio de Partos, Hospital Universitario del Valle. Cali, Colombia.

\section{Pacientes y métodos}

Se seleccionaron 20 pacientes embarazadas que ingresaron al Servicio de Obstetricia del Hospital Universitario del Valle (HUV) en el $2^{\circ}$ semestre de 1996. Diez 

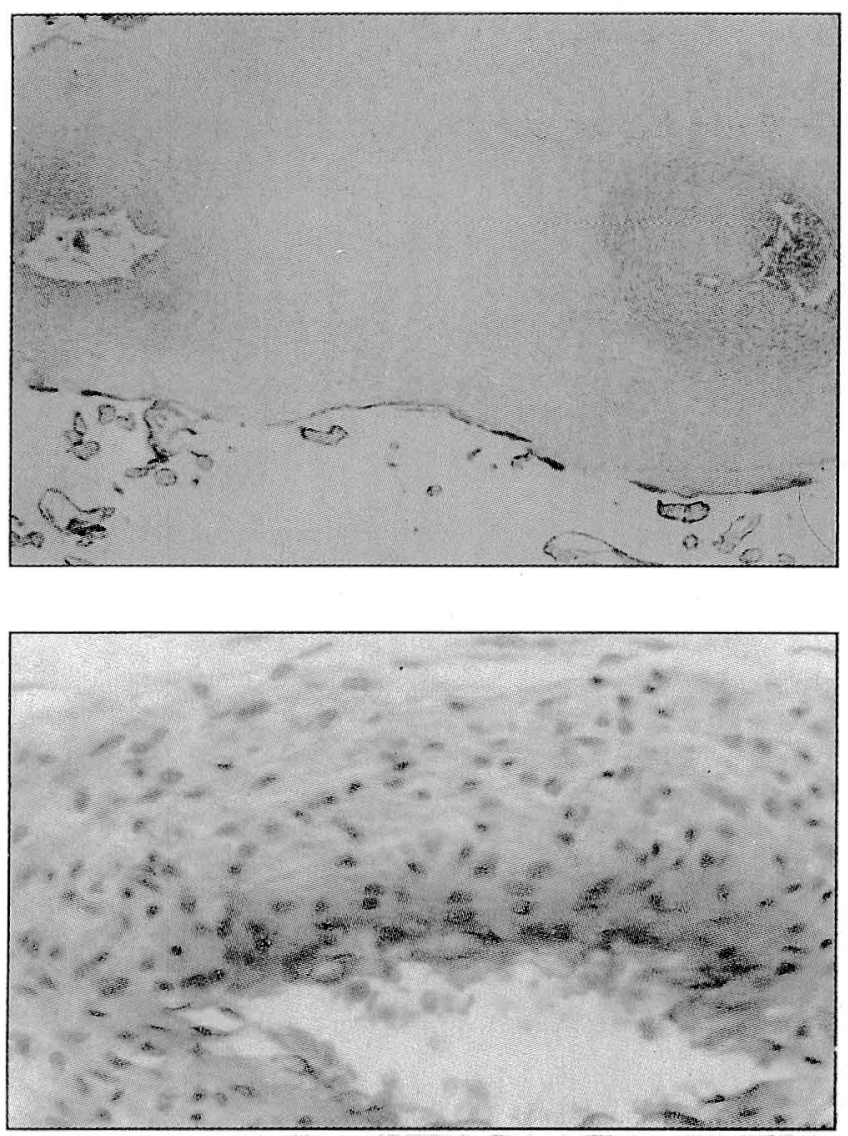

Figura 1a. (arriba) y 1b. (abajo).

Microscopía de luz (por 10 y 40 aumentos respectivamente). Hematoxilina y Eosina. Biopsia de placenta ("cara materna") en post-parto de paciente eclámptica. Podemos observar en ambas fotografías (parte izquierda Figura la y en toda la Figura lb), arterias de vellosidad coriónica con estrechamiento de su luz, necrosis fibrinoide y depósito de lípidos en sus paredes (Aterosis).

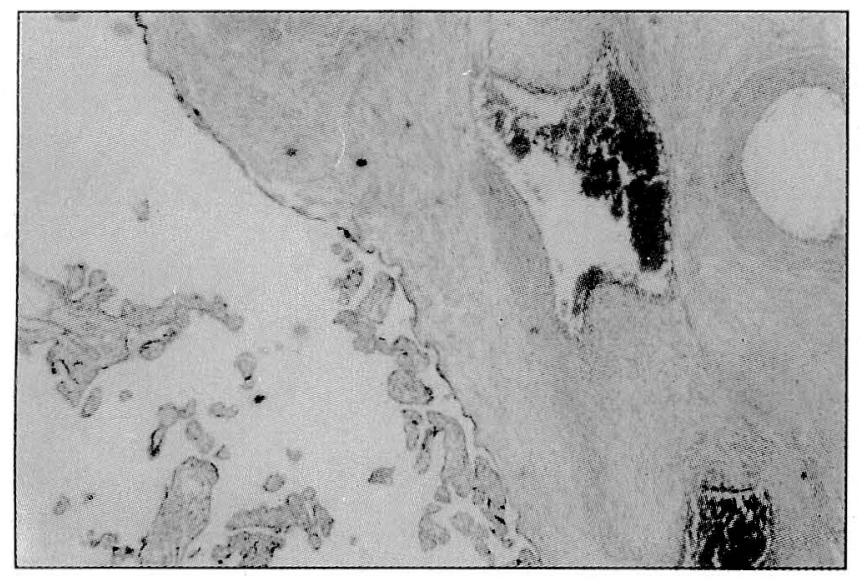

Figura 2. Microscopía de luz (por 10 aumentos). Hematoxilina y Eosina. Biopsia de placenta ("cara materna") en postparto de paciente eclámptica. Se observa (a la derecha) engrosamiento de la capa media de un vaso de vellosidad coriónica a expensas de colágeno. Nótese además la hialinización difusa del estroma. Estos cambios no se visualizaron en las placentas de embarazadas normales (Figura 3).

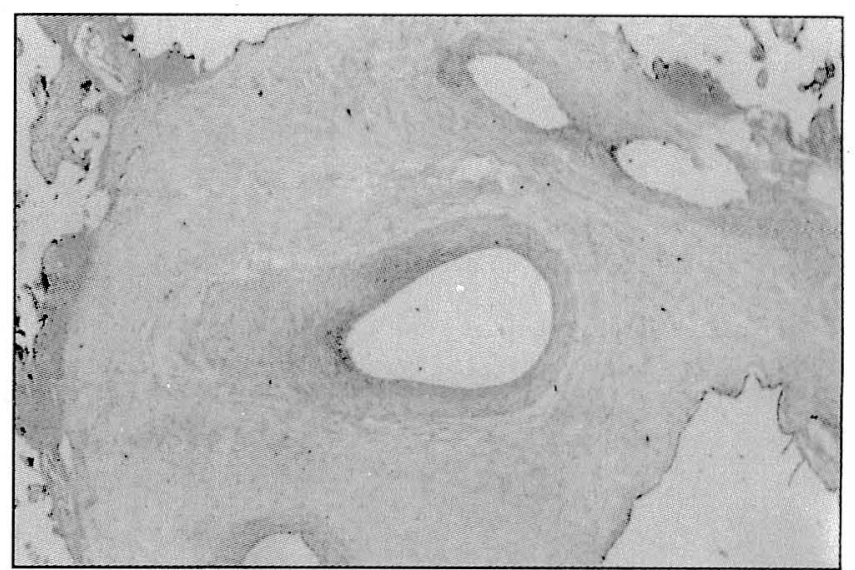

Figura 3. Microscopía de luz (por 10 aumentos). Hematoxilina y Eosina. Biopsia de placenta proveniente de embarazada sin patología. Podemos observar (en el centro de la fotografía) un vaso de vellosidad coriónica con una luz amplia y paredes lisas. No hay alteraciones en el estroma, ni cambios de aterosis.

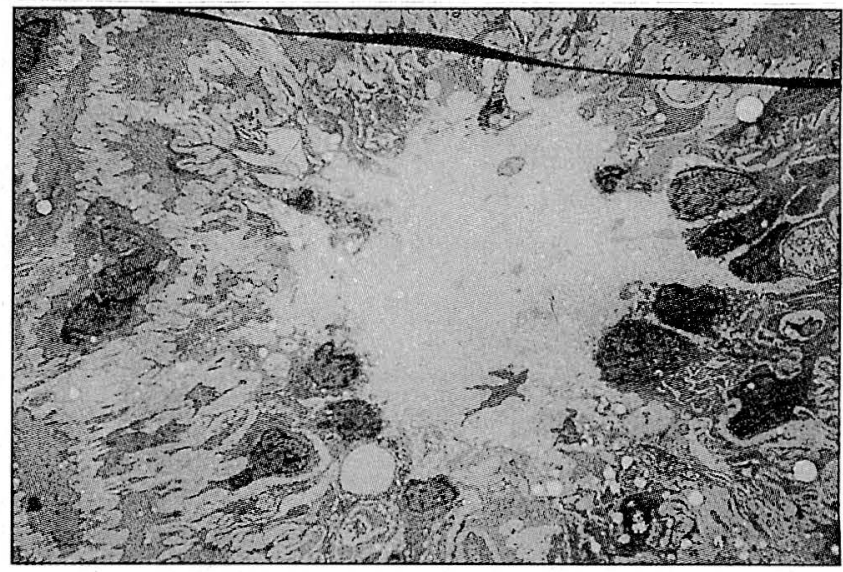

Figura 4. Microscopía electrónica de transmisión (2000 aumentos). Biopsia de cotiledón placentario en una paciente eclámptica. Se observa protrusión de las células endoteliales hacia la luz del vaso y presencia de abundantes vacuolas lipídicas (expresión morfológica del daño endotelial).

(10) presentaban Eclampsia (Hipertensión Arterial Inducida por el Embarazo proteinúrica y con convulsiones tónico-clónicas generalizadas). Una vez producido el parto y después del alumbramiento se tomó la placenta (en su superficie materna) y se realizó biopsia en cuña de un cotiledón. La muestra se fijó utilizando la técnica de Milloning (formol al 10\% y glutaraldehido al $2.7 \%$, pH 7.2 y una concentración 0.1 Molar). Simultáneamente se obtuvo biopsia en cuña de placenta post-parto en otras 10 embarazadas sin ninguna patología detectable y con parto completamente normal.

El procedimiento para microscopía de luz fue el siguiente: Se realizaron cortes a 5 micras, se colorearon con hematoxilina y eosina, se observaron al microscopio con aumento de 10X, 40X y $100 \mathrm{X}$. 

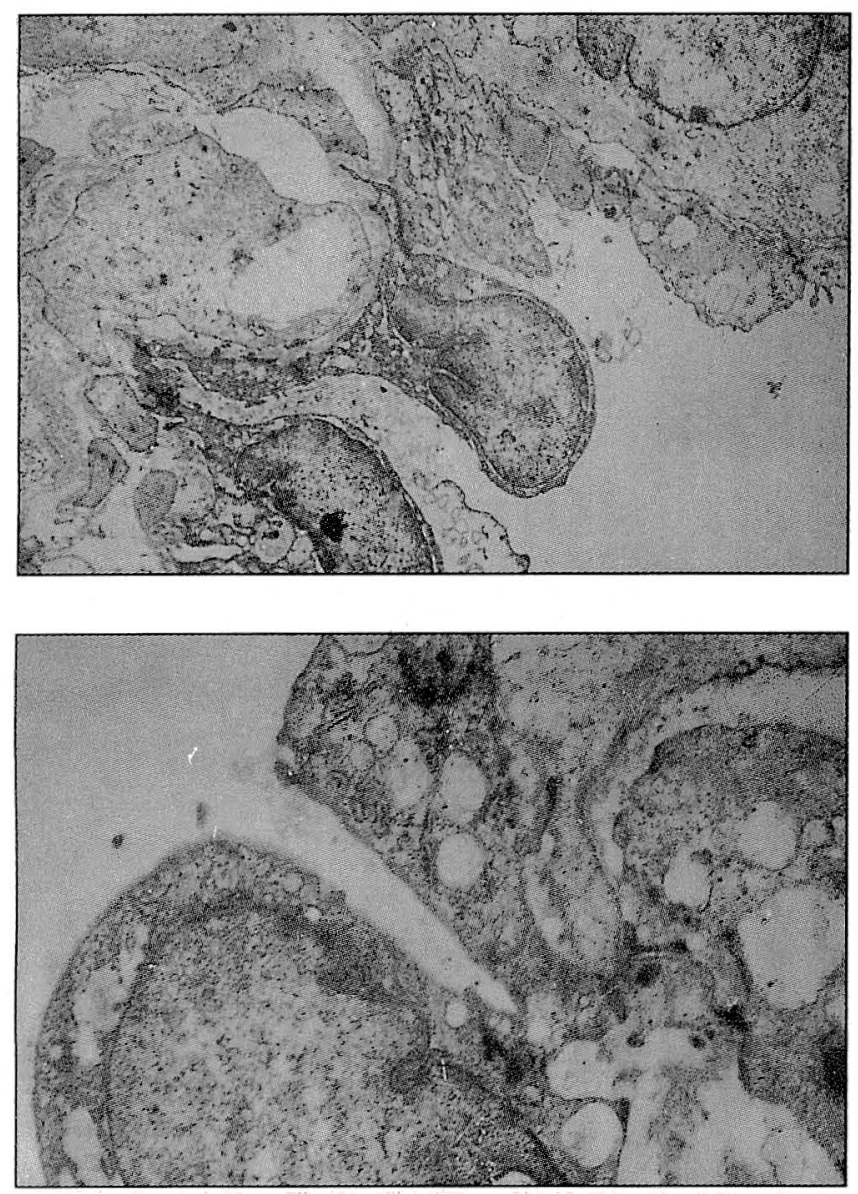

Figuras 5a (arriba) y 5b (abajo).

Microscopía electrónica de transmisión (3000 y 10000 aumentos respectivamente). Paciente eclámptica. Es evidente el marcado daño

en el citoplasma, manifestado por la presencia de abundantes vacuolas lipídicas. No se observan las organelas intracitoplasmáticas principalmente el retículo endoplásmico rugoso (sitio donde se producen, entre otras substancias, el oxido nítrico y la prostaciclina). Favor comparar con las figuras $6 \mathrm{a}$ y $6 \mathrm{~b}$.

Para microscopía electrónica de transmisión se realizaron cortes de $500 \mathrm{~A}^{\circ}$ y se procedió a contrastar mediante técnica de Reynoldg con acetato de plomo y citrato de sodio. Se hicieron observaciones entre 2000 y 5000 aumentos.

Para la miscroscopía electrónica de barrido se fraccionaron las biopsias en segmentos de 5 a 10 milímetros. Cada segmento previa deshidratación en serie alcohólica de graduación, se introdujo en cámara al vacío y se expuso a un flujo de dióxido de carbono $(\mathrm{CO} 2)$ líquido (con el fin de evitar el desplazamiento celular durante el proceso). A continuación la muestra se introdujo en un orificador al vacío con alta temperatura (100 a 140 grados centígrados) con el objetivo de impregnar el tejido de partículas de oro para lograr una adecuada refracción de los electrones secundarios. Se hicieron observaciones entre 150 y 3500 aumentos. Con éste método ("de barrido") se buscó objetivizar cambios en la superficie del endotelio vascular.
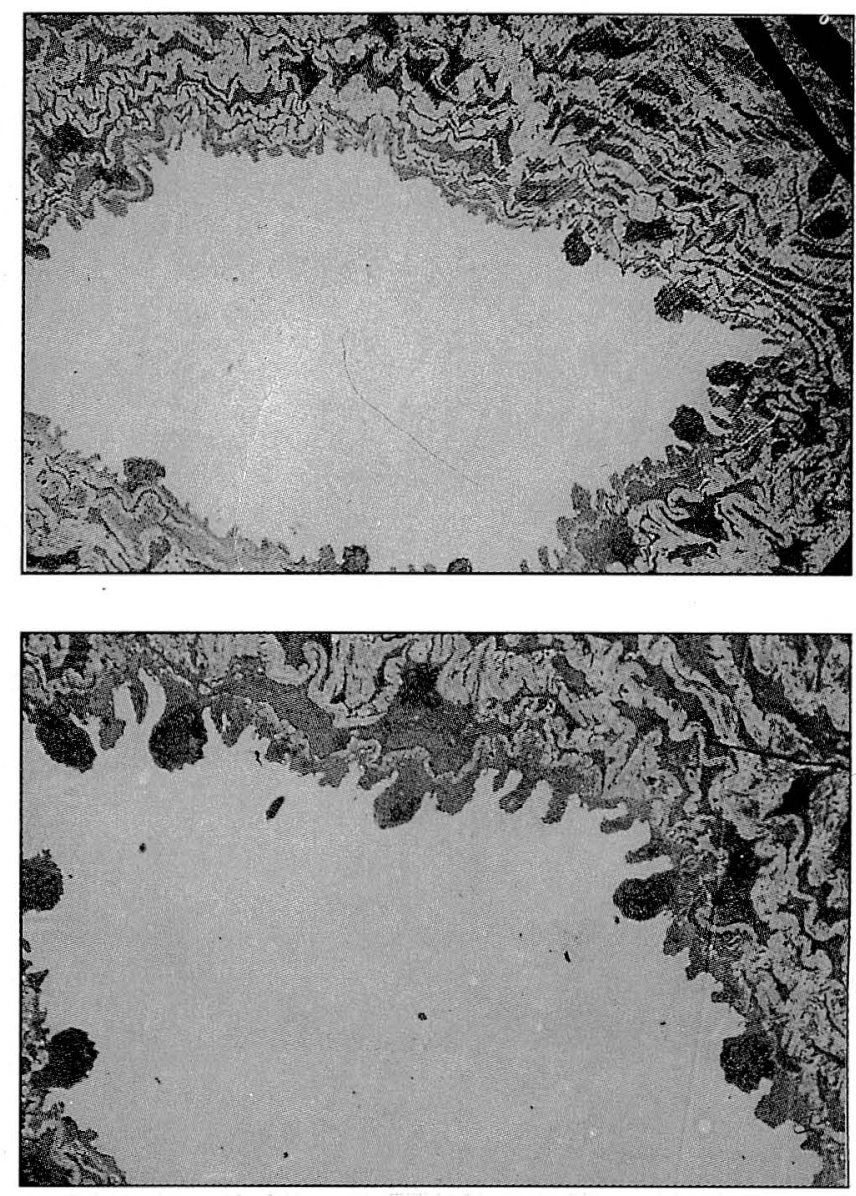

Figuras 6a (arriba) y $6 \mathrm{~b}$ (abajo).

Microscopía electrónica de transmisión con 1000 y 2000 aumentos respectivamente. Biopsia de vellosidad coriónica en una paciente normal. Podemos observar las células endoteliales dispuestas regularmente en la luz del vaso sin ningún signo morfológico de alteración estructural.

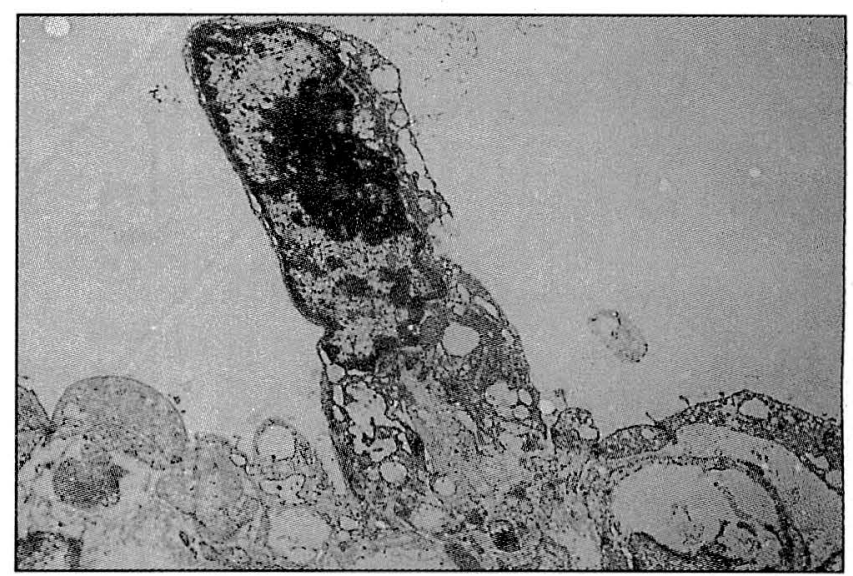

Figura 7. Microscopía electrónica de barrido (1000 aumentos). Vellosidad coriónica de una paciente eclámptica. Podemos observar marcada protrusión celular hacia la luz endotelial del vaso. Además hay presencia de abundantes vacuolas lipídicas (signo de destrucción celular). 

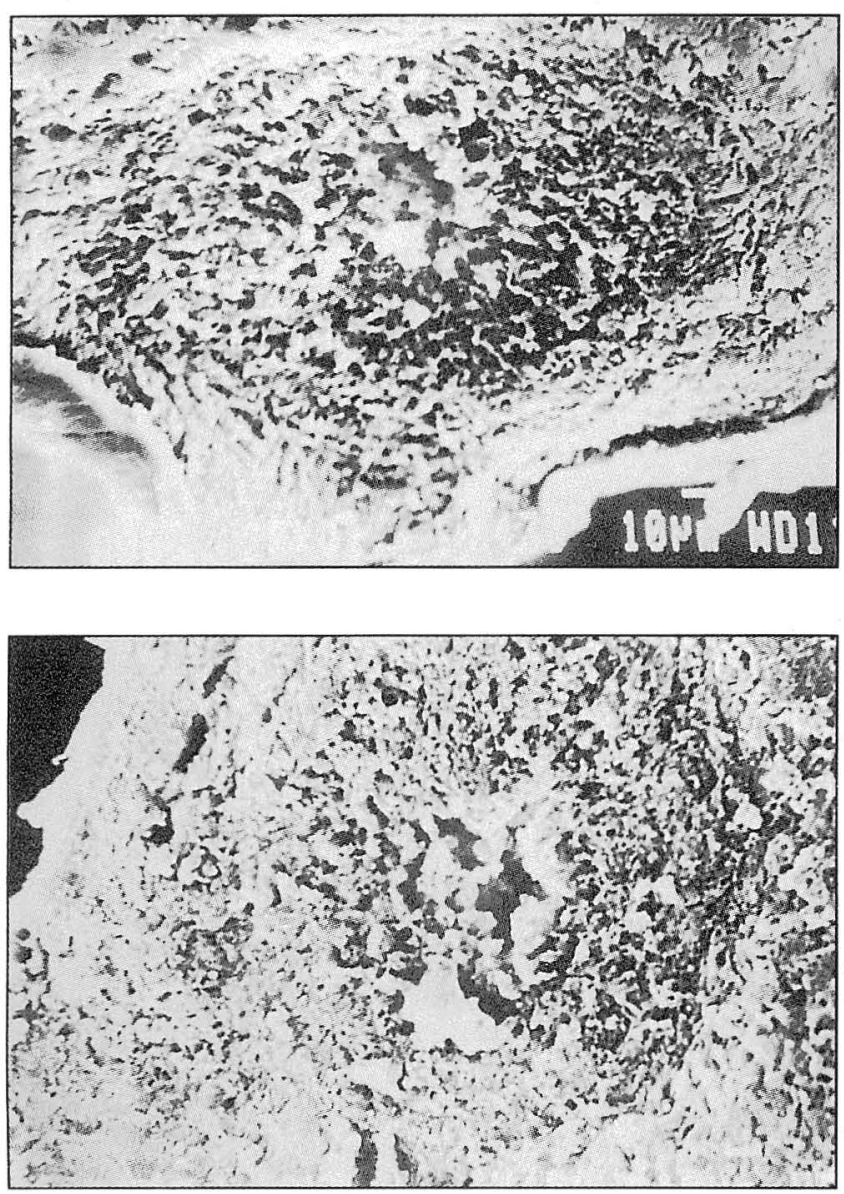

Figura 8a (arriba) y 8 b (abajo).

Microscopía electrónica de barrido. Paciente eclámptica (430 y 400 aumentos respectivamente). Se observa en ambas microfotografías obliteración casi total de la vasculatura de vellosidad placentaria, ocasionada por protrusión de las células endoteliales y depósito de material fibrilar. Comparar con Figura 9

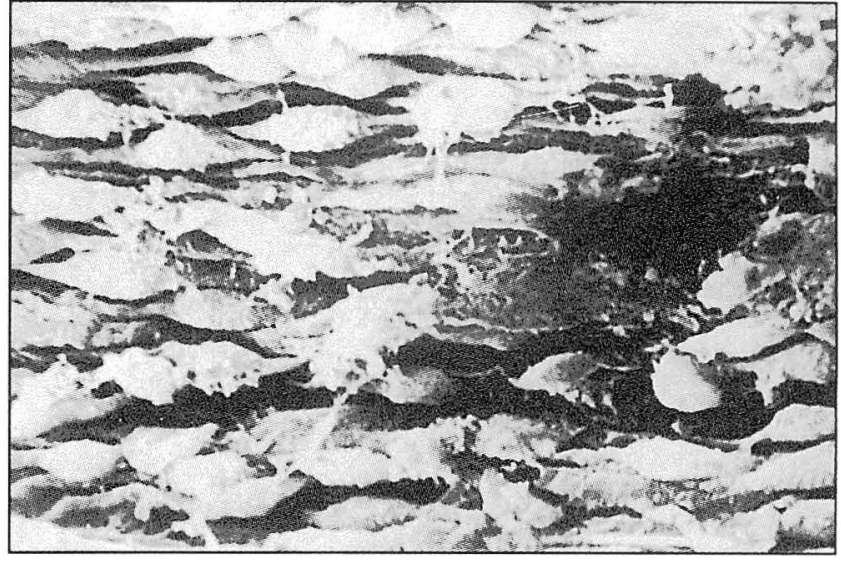

Figura 10. Microscopía electrónica de barrido 1600X. Paciente eclámptica. Biopsia de cotiledón placentario. Microfotografía de la superficie del piso vascular. Podemos observar células endoteliales engrosadas, dispuestas irregularmente con espacios entre ellos (que corresponden a "poros"), así como también abundante material fibrilar. Estos cambios ultraestructurales indican daño marcado del tejido endotelial.

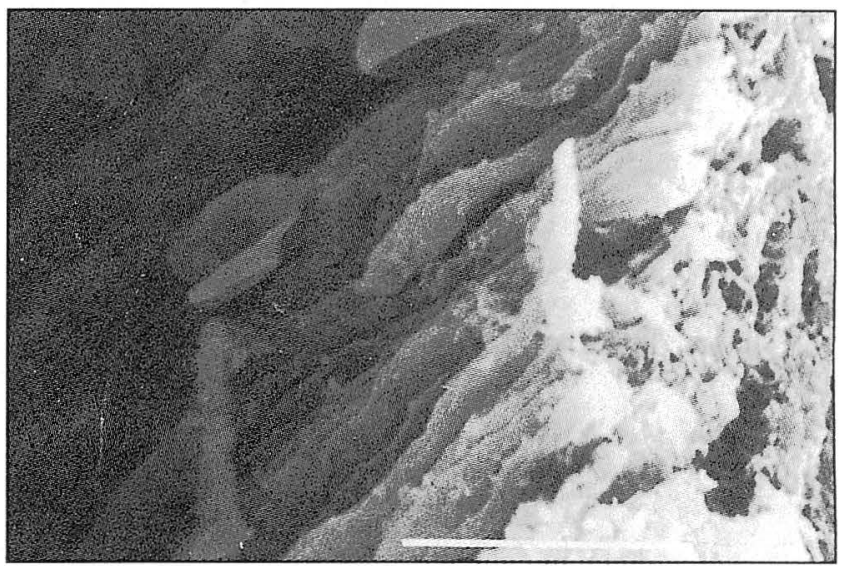

Figura 11. Microscopía electrónica de barrido. 3500X. Embarazo normal. Se observa la disposición de las células endoteliales en el piso de un vaso, adoptando el patrón "en tejado español". Se observan además algunos eritrocitos. Comparar con Figura 10.

\section{Resultados}

Microscopía de luz. En la vasculatura placentaria de las embarazadas con eclampsia se observó necrosis fibrinoide con depósitos de lípidos intramurales, cambios conocidos como aterosis (Figuras 1a y 1b). Las arterias son estrechas con diámetro irregular por obliteración de su luz. Además, hay engrosamiento de la capa media del vaso a expensas de colágeno y hialinización del estroma en forma difusa (Figura 2). Estos cambios no se observaron en las placentas de embarazadas normales (Figura 3 ).

Microscopía electrónica de transmisión. En todas las placentas de eclampsia de observó protrusión de las 
células endoteliales hacia la luz del vaso (Figura 4) con marcado daño en el citoplasma manifestado por la presencia de vacuolas lipídicas que impiden identificar las organelas intraplasmáticas principalmente el retículo endoplasmático rugoso (Figuras 5a y 5b). Estos cambios no se observaron en las muestras analizadas de las pacientes normales cuyas células endoteliales conservaron la distribución normal (Figuras 6a. y 6b).

La protrusión de las células en la luz endotelial y la presencia de vacuolas lipídicas además de ser un hallazgo constante fue más marcado en algunas eclámpticas (Figura 7).

Microscopía electrónica de barrido. Con ésta técnica se pudo observar obliteración total del vaso de la vellosidad coriónica, producida por protrusión del endotelio hacia la luz vascular (Figuras 8 a y 8 b). Esto se hizo más evidente al comparar vasos de pacientes eclámpticas con vasos de vellosidades coriónicas provenientes de embarazadas normales, los cuales mostraron una luz amplia con un tejido endotelial cuyas células se disponen de una manera regular (Figura 9).

Al realizar microdisección del vaso placentario para mejor visualización de la superficie del piso vascular observamos células endoteliales engrosadas dispuestas irregularmente con espacios entre ellas que corresponden a poros y abundante material fibrilar, expresión ultraestructural del daño celular endotelial (Figura 10). Estos cambios no se observaron en el tejido endotelial de los vasos sanguíneos de vellosidades coriónicas procedentes de embarazadas normales, las cuales presentan células endoteliales de superficie lisa, sin poros, sin material fibrilar y en disposición regular "en tejado español"(Figura 11).

\section{Conclusiones}

Actualmente se considera que la falla en la segunda etapa de migración del trofoplasto (que ocurre normalmente entre las semanas 16 y 22 de la gestación) es la más temprana alteración que se presenta en la toxemia (Hipertensión Arterial Inducida por el Embarazo, proteinúrica) (1-2).

Por otra parte, la Eclampsia es la comprobación clínica inequívoca de que una embarazada ha desarrollado toxemia. Este es el motivo por el cual realizamos biopsias solamente en placentas de embarazadas con eclampsia.

Creemos que el presente estudio llevado a cabo con pacientes eclámpticas sirve para objetivizar más la existencia de un proceso vascular obstructivo desencadenado por una placentación anormal y evidenciado morfológicamente por aterosis (3-4) de características muy similares a la lesión arterial que se observa en el rechazo del transplante renal (5).

Consideramos a su vez que éste proceso obstructivo genera un evento isquémico con hipoperfusión a nivel sistémico y también a su vez a nivẹl del lecho vascular placentario. Ello se demuestra por los cambios celulares en el endotelio de la vasculatura placentaria de todas las pacientes eclámpticas estudiadas en este trabajo.
Entre los cambios ultraestructurales observados por nosotros en las pacientes eclámpticas eštán: depósito de fibrina, lípidos, proliferación muscular y destrucción de organelas celulares, entre estas retículo-endoplásmico rugoso, sitio de producción del óxido nítrico (potente vaso dilatador) y de la prostaciclina (potente vaso dilatador inhibidor de la agregación plaquetaria y de la contractilidad uterina). Las alteraciones en el retículo endoplásmico rugoso (evidenciadas en la ultramicroscopía de transmisión) llevarían a depleción en óxido nítrico y prostaciclina con desencadenamiento y/o agravación del problema hipertensivo. Estos cambios han sido publicados recientemente en placentas de ratas preñadas a las cuales se les administró un inhibidor de la enzima sintetasa del óxido nítrico (6). Así como también en la caracterización inmunohistoquímica de la expresión de sintetasa de oxido nítrico en placentas de preeclámpticas (7).

Este modelo explica además las alteraciones en el sistema renina-angiotensina - aldosterona (SRAA). En éste sistema el angiotensinógeno se convierte en angiotensina I (inactiva). Esta a su vez se convierte en angiotensina II (biológicamente activa) por una enzima convertidora de angiotensina (ECA) producida en las células endoteliales de los vasos. En la preeclampsia los componentes del SRAA se disminuyen alterándose el control del tono vascular de la presión sanguínea. Las características clínicas de la toxemia como edemas y pérdida de proteínas por el capilar renal son expresión de alteración en la función de transporte del endotelio normal. Más aún, consideramos que las alteraciones morfológicas descritas en este trabajo apoyan la teoría de una disfunción celular endotelial que altera la producción de óxido nítrico (por el retículo endoplásmico rugoso), así como también la producción y relación entre tromboxano (vasoconstrictor agregante plaquetario) y prostaciclina (vaso dilatador e inhibidor de agregación plaquetaria), cuya expresión clínica es la hipertensión inducida por el embarazo con proteinuria (7).

Estas lesiones de las células endoteliales también explican, las alteraciones en la hemostasia que se observan en la toxemia y que se expresan por la agregación plaquetaria, disminución en la síntesis de sustancias como el factor VIII, B- tromboglobulina y antitrombina III y aumento en los valores de fibronectina (8-9).

En resumen, hemos querido mostrar (por primera vez en la eclampsia) los cambios ultraestructurales por microscopía de luz, de transmisión y de barrido que se suceden en el tejido endotelial de la vasculatura placentaria de éstas pacientes, cambios histológicos que no observamos comparativamente en placentas de embarazadas normales. Estas alteraciones morfológicas descritas por nosotros en el retículo endoplásmico rugoso de la célula endotelial podrían explicarnos las manifestaciones clínicas observadas en las mujeres con Hipertensión Inducida por el Embarazo proteinúrica, enfermedad ésta que constituye la primera causa de Mortalidad Materna en nuestro medio. 


\section{BIBLIOGRAFIA}

1. Chesley LC. Hypertensive disorders in pregnancy. New York: Appleton- Century- Crofts, 1978.

2. Meekins JW, Pijnenborg R, Hanssens M, McFadyen IR, Van Asshe A. A study of placental bed spiral arteries and trophoblast invasion in normal and severe pre-eclamptic pregnancies. Br J Obstet and Gynecol, 1994; 101: 669-674

3. Zeek PM and Assali NS. Vascular changes in the decidua associated with eclamptogenic toxemia of pregnancy. Am J Clin Pathol, 1950; 20: 1099-109

4. Sheppard BL, Bonnar J. An ultraestructural study of utero-placental spiral arteries in hypertensive and normotensive pregnancy and fetal growth retardation. Br J Obstet Gynecol, 1981; 88: 695-705.

5. Dempster WJ, Harrison CV and Shackman R. British Medical Journal, 1964: 2: 969-978.
6. Osawa H. Study on the morphological changes in the placenta of rats administered nitric oxide synthase inhibitory. Nippon Sanka Fujinka Gakkai Zasshi, 1996; 48: 813-820

7. Ghabour MS, EIS AL, Brickman DE. Inmunohistochemical characterization of placental nitric oxide synthase expression in preeclampsia. Am J Obstet Gynecol, 1995; 173: 687-694.

8. Roberts JM, Taylor R, Musci Th J, et al. Preeclampsia : an endothelial cell disorder. Am J. Obstet Gynecol, 1989; 161: 1200-1204

9. Lockwood C, Peters J. Increased plasma levels of EDI + Cellular fibronectin precede the clinical signs of preeclampsia. Am J Obstet Gynecol, 1990; 162: 358-368.
Correos de Colombia

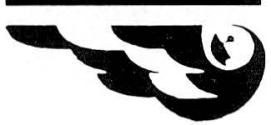

- SERVICIO ENCOMIENDAS ASEGURADAS

- SERVICIO CARTAS ASEGURADAS

- SERVICIO DE GIROS

- BUROFAX

- SERVICIO "CORRA"

- SERVICIO DE CORREO ORDINARIO

\section{Estos son nuestros servicios jutilícelos!}

\author{
- SERVICIO DE CORREO CERTIFICADO \\ - SERVICIO DE CERTIFICADO ESPECIAL \\ - ENCOMIENDAS CONTRA REEMBOLSO \\ - SERVICIO TARIFA POSTAL REDUCIDA \\ - SERVICIO DE FILATELIA \\ - SERVICIO ELECTRONICO \\ - SERVICIO INTERNACIONAL APR/SAL \\ - SERVICIO RESPUESTA COMERCIAL \\ - SERVICIOS ESPECIALES
}

Teléfonos para quejas y reclamos: 3340304 - 3415536 - Santafé de Bogotá, D.C. - Colombia Cuente con nosotros hay que creer en los Correos de Colombia 